\title{
Presentation of a Validated Checklist as a Tool for Assessing, Preventing and Managing Food Waste in Foodservices
}

\author{
Tânia Regina Kinasz ${ }^{1}$, Regina Baptista Reis' ${ }^{1}$, Tania Beninga Morais ${ }^{2 *}$ \\ ${ }^{1}$ Departament of Food and Nutrition, Universidade Federal de Mato Grosso, Cuiabá, Brazil \\ ${ }^{2}$ Postgraduate Programme in Nutrition, Food Quality Control Laboratory, Universidade Federal de São Paulo, \\ São Paulo, Brazil \\ Email: trkinasz@hotmail.com, nutricao@ufmt.br,
}

Received 7 July 2015; accepted 8 August 2015; published 13 August 2015

Copyright (C) 2015 by authors and Scientific Research Publishing Inc.

This work is licensed under the Creative Commons Attribution International License (CC BY).

http://creativecommons.org/licenses/by/4.0/

(c) (i) Open Access

\begin{abstract}
More researches are needed to identify the relevant factors influencing the generation of food waste and devise preventive strategies. The objective of this study is to develop a checklist to assess the good management practices that have a positive impact on eliminating or minimizing food waste in food service units. A theoretical list of relevant factors impacting the generation of food waste during meal production is developed, taking into account administrative planning, receipt and storage of foods, and the preparation and distribution of meals by food service units. For each factor, several administrative and/or technical actions are identified. To validate the content, this list is submitted to a ten-member expert panel for a final evaluation. The factor (and its respective actions) is considered relevant if $80 \%$ of the expert panel members agree on its relevance. All actions employ a dichotomous response of Yes/No. Affirmative responses are expected because these actions are considered to be good management practices that have a positive impact on eliminating or minimizing food waste. Following the panel approval process, a checklist of 12 factors and 102 actions is detailed. The conceptual structure of the checklist for food waste management presented in this study enables a comprehensive understanding of the factors that impact food waste, providing a theoretical basis for future research into the relative importance of the relevant factors and actions identified in this study.
\end{abstract}

\section{Keywords}

Food Services, Checklist, Food Wastefulness, Waste Management

\footnotetext{
"Corresponding author.
} 


\section{Introduction}

Despite bringing increased prosperity to more people, the economic development of the last few decades has produced ecological imbalances, such as climate change and the thinning of the ozone layer. These consequences have led to the creation of a new concept: sustainable development. Over the last two decades, public opinion has become increasingly aware, demanding measures to protect the environment from both economic agents and the government. The generation of solid waste is a natural consequence of human life. Among solid waste, food waste forms the major component in municipal landfills [1] [2]. In addition to ethical issues, wasting edible food has negative economic, environmental and social impacts [3]. Though foodservices are in a unique position to manage food waste, no studies have been reported in the literature during recent years on the causes of food waste within this stage of the food supply chain. The studies on food waste have focused on measuring plate waste (food served in the plate and not consumed) and overproduction (food prepared and not served) [4][9]. However, reasons behind why these wastes occur were not investigated. More researches are therefore needed to identify the relevant factors influencing the generation of food waste and devise preventive strategies. The objective of this study is to develop a checklist to assess good management practices that have a positive impact on eliminating or minimizing food waste in institutional food service units.

\section{Methods}

Theoretical framework used in the development and validation of psychological assessment instruments [10] was applied to develop a checklist of relevant factors in the generation of food waste in foodservices. Based on the literature [4]-[9] and in the authors' experience, a theoretical list of relevant factors impacting the generation of food waste during meal production was developed, taking into account administrative planning, the receipt and storage of foods, and the preparation and distribution of meals in food service units. For each factor, a number of administrative and/or technical items were identified. The formulation of items took into account the criteria of behavior (expressing an action); simplicity (being limited to a single action); clarity (being intelligible); relevance (being pertinent to what the item is supposed to measure) and modality (being formulated to avoid extreme expressions). To validate the content, this list was submitted to a ten-member expert panel for a final evaluation [10]. Seven members were faculty, each with at least ten years academic and scientific experience in the field, and three members were nutritionists with at least five years of experience managing food service units. They analyzed the coherence of the items and their relevance to what was being measured, accordingly to their expertise. The factor (and its respective items) was considered relevant when $80 \%$ of the expert panel members agreed on its relevance [11].

Following the panel approval process, a checklist of 12 factors and 102 actions was detailed. All actions employ a dichotomous response of Yes/No. Affirmative responses are expected because these actions are considered to be good management practices that have a positive impact on eliminating or minimizing food waste. These actions should be assessed by systematic observation and by consulting administrative records. The Kuder Richardson Coefficient (K-R 20) for binary measurements was used to test the checklist reliability [12]. The result was 0.971, indicating a homogenous set of data [13]. The package Statistical Package for the Social Sciences (SPSS), version 19.0 for Windows was used for this analysis. This study was approved by the Ethics Committee of the Universidade Federal de São Paulo.

\section{Results}

Table 1 to Table 12 present the 102 actions of the 12 factors that are relevant to food waste in institutional food service units that are approved by the expert panel.

\section{Discussion}

Institutional foodservices should surpass standard sustainable strategies, such as using resources efficiently, collecting materials for recycling and reusing, and composting food waste [14]. Understanding how food waste occurs and identifying its main sources will allow food service managers to act preventively. Thus, the scope of this study is to develop a comprehensive and a content validated checklist in the topic of food waste with a preventive, practical approach, focusing on actions toward elimination or minimization of food waste in order to 
Table 1. Actions for the factor "Knowing the profile of the patrons improves the quality and quantity of meals and contributes toward preventing food waste”.

\section{Actions (Yes/No)}

Does the dietetic professional know the estimated number of patrons to be served on any given day?

Does the dietetic professional know the gender distribution of the patrons?

Does the dietetic professional know the food habits and preferences of the patrons?

Does the dietetic professional know the age range of the patrons?

Does the dietetic professional know the education level of the patrons?

Does the dietetic professional know the socioeconomic status of the patrons?

Does the dietetic professional know the level of physical activity the patrons engage in at work?

Does the dietetic professional know the religion of the patrons?

\section{Table 2. Actions for the factor "Careful menu planning contributes toward preventing food waste".}

\section{Actions (Yes/No)}

Does the dietetic professional accurately forecast the quantities of food needed based on the menu and the number of patrons?

Does the dietetic professional standardize the recipes?

Does the dietetic professional take into account the yield of vegetables?

Does the dietetic professional take into account the yield of fruits?

Does the dietetic professional take into account the yield of meats?

Does the dietetic professional take into account the yield of cereals?

Does the dietetic professional take into account food seasonality?

Does the dietetic professional take into account the regional climate?

Are the meals planned to show pleasing food color combinations?

Are the meals planned to include pleasing food taste combinations?

Are the meals planned to include pleasing food texture combinations?

Are the resources sufficient for a varied menu?

Does the dietetic professional set meat cutting specifications?

Does the dietetic professional set vegetable cutting specifications?

Does the dietetic professional set fruit cutting specifications?

Does the dietetic professional specify the cooking techniques?

Table 3. Actions for the factor "Careful menu execution contributes toward preventing food waste".

\section{Actions (Yes/No)}

Does the storage clerk comply with the foodstuff quantities ordered by the kitchen staff?

Do the staff members comply with the meat cutting specifications?

Do the staff members comply with the vegetable cutting specifications?

Do the staff members comply with the fruit cutting specifications?

Do the staff members in charge of cooking comply with the specified cooking techniques?

Do the staff members comply with applying standardized recipes according to the number of patrons?

Do the staff members comply with maintaining the required holding temperature between food preparation and service? 


\section{T. R. Kinasz et al.}

Table 4. Actions for the factor "Proper practices during the distribution of meals contribute toward preventing food waste".

\section{Actions (Yes/No)}

Does the staff monitor food holding temperatures in the steam tables and salad buffets?

Are standardized food service utensils used?

Do the food service workers serve the patrons with agility and speed?

Is the dining area kept clean and well-arranged during the course of the meal?

\section{Table 5. Actions for the factor "Pleasant dining area ambience contributes toward preventing food waste".}

\section{Actions (Yes/No)}

Does the layout of the dining area offer comfort to the patrons?

Are the physical layout and dimensions of the steam tables and salad buffets chosen according to the number of patrons to be served and the time allowed for meals?

Is the ambient temperature controlled?

Is the ambient illumination comfortable?

Is the ambient ventilation comfortable?

Is the ambient humidity comfortable?

Table 6. Actions for the factor "Applying good food handling practices and standard operating procedures manuals, besides improving food safety, contribute toward preventing food waste by spoilage".

Does the foodservice unit have a Good Food Handling (GFH) practices manual?

Does the foodservice unit have a Standard Operating Procedures (SOP) manual?

Are GFH practices and SOP manuals continually updated?

Are job descriptions incorporated into GFH practices and SOP manuals?

Does the dietetic professional carry out performance reviews to check whether the staff members are complying with their job descriptions?

Table 7. Actions for the factor "Proper human resources management contributes toward preventing food waste".

Actions (Yes/No)
Is the staff workload properly allocated?
Do the foodservice workers have written job descriptions?
Are there written work schedules to guide the staff activities during the work day?
Is the workload eight hours a day?
Do the employees work overtime?
Does the dietetic professional control when the employees are absent from work?
Is the staff skillful in their tasks?
Does the staff have the technical expertise to perform specific tasks?
Is there training for all staff members?
Is the training both theoretical and practical?
Is the interval between training sessions less than six months?


Table 8. Actions for the factor "The dietetic professional's good management practices and work supervision contribute toward preventing food waste”.

\section{Actions (Yes/No)}

Does the dietetic professional supervise the work of the staff during food operation?

Is the dining area kept clean and well-arranged during meal time?

Is the dietetic professional able to control overproduction?

Is the dietetic professional able to control plate waste?

Are there surveys addressing the level of patron satisfaction with the menus?

Are the menus changed according to the wishes of patrons?

Is there a campaign to increase patrons awareness of plate waste?

Is there a preventive equipment maintenance plan?

Table 9. Actions for the factor "Good management practices during purchasing and receipt contribute toward preventing food waste".

\section{Actions (Yes/No)}

Does the dietetic professional forecast the expected amount of time before a food item should be purchased?

Has the dietetic professional developed food specifications?

Does the dietetic professional specify units of measure in purchasing orders?

Does the dietetic professional request a particular expiration date when purchasing a food item?

Does the dietetic professional select only approved sources of foods?

Does the dietetic professional select and establish a variety of purveyors to ensure supply options?

Do the purveyors comply with the requested food expiration dates?

Do the purveyors comply with the food quality specifications?

Do the purveyors provide the food quantities ordered?

Do the purveyors comply with the transportation standards for perishable and non-perishable foods?

Does the receiving clerk check the food received for quantity and against the purchasing specifications for quality and type, according to the purchase order and the invoice?

Does the receiving clerk check the food received to ensure undamaged packaging?

Does the receiving clerk check the food received for expiration dates?

Does the receiving clerk check the temperature of the perishable food received?

Table 10. Actions for the factor "Good management practices during storage and in the inventory control of foods contribute toward preventing food waste".

\section{Actions (Yes/No)}

Do the storage areas have adequate dimensions for storing all food-related items?

Do the storage areas meet the specifications for walls, ceilings, floors, windows, baseboards, floor drains, lightning and ventilation?

Does the dry storage area protect the food from direct sunlight, heat, moisture and smoke?

Is there a cleaning schedule for the storage areas?

Do the dry storage area and the walk-in refrigerators have insect and rodent control?

Is the temperature of the dry storage area checked by a thermometer located near the door?

Are there separate walk-in refrigerators for 1) fruits and vegetables; 2) meats, poultry and fish; and 3) eggs and milk?

Are the walk-in refrigerators checked for temperature and relative humidity using a temperature and humidity logger?

Is the stock rotated according to the expiration dates?

Is the stock rotated according to proper first-in, first-out (FIFO) practices? 
Table 11. Actions for the factor "Having a waste management plan contributes toward preventing food waste".

Actions (Yes/No)
Does the dietetic professional have knowledge of the legislation regarding waste management?
Is the waste management plan implemented in the foodservice unit?
Are corrective actions planned in the waste management plan?
Are the staff members trained on the waste management plan implemented in the foodservice unit?
Does the training cover the process flow, types and factors that generate waste in the foodservice unit?
Are uses planned for the non-conventional edible parts of foods?
Table 12. Actions for the factor "Proper working conditions prevent errors and accidents, contributing toward minimizing
food waste”.
Are the physical layouts of the work areas suitable?
Is the ambient temperature in the work areas suitable?
Is the ambient noise in the work areas suitable?
Is the ambient illumination in the work areas suitable?
Is the ambient ventilation in the work areas suitable?
Is the ambient humidity in the work areas suitable?
Is Personal Protective Equipment (PPE) available to the workers?
Are the workers trained on proper use of PPE?
Do the workers wear PPE?

help foodservices managers in the managing of food waste. In our knowledge, this is a new and innovative checklist.

The lack of studies in identifying the main sources of food waste and why they occur prevents providing references related to the connections between the factors identified in this study and food waste. This fact shows that the many gaps in the knowledge existing in this subject need to be addressed. The main limitation of this study is the lack of testing in a "real world" situation. However, instead, the aim of this study is to provide to foodservices managers and researchers in this field a validated tool to support further studies.

In conclusion, the conceptual structure of the checklist on food waste management presented in this study enables a comprehensive understanding of the factors impacting food waste and forms a theoretical basis for future research into the relative importance of each relevant factor and its corresponding actions identified in this study.

\section{Acknowledgements}

This research received no specific grant from any funding agency in the public, commercial or not-for-profit sectors. The authors state that there are no conflicts of interest. T.R.K. participated in conception and design of the study, in acquisition, analysis and interpretation of data, and in drafting the manuscript; R.B.R. participated in conception and design of the study; T.B.M. participated in conception and design of the study, in analysis and interpretation of data, and in revising the manuscript, and has given final approval for this version to be published. All authors read and approved the final manuscript.

\section{References}

[1] Gidarakos, E., Havas, G. and Ntzamilis, P. (2006) Municipal Solid Waste Composition Determination Supporting the Integrated Solid Waste Management system in the Island of Crete. Waste Management, 26, 668-679. http://dx.doi.org/10.1016/j.wasman.2005.07.018 
[2] Saeed, M.O., Hassan, M.N. and Mujeebu, M.A. (2009) Assessment of Municipal Solid Waste Generation and Recyclable Materials Potential in Kuala Lumpur, Malaysia. Waste Management, 29, 2209-2213. http://dx.doi.org/10.1016/j.wasman.2009.02.017

[3] Schneider, F. (2013) Review of Food Waste Prevention on an International Level. Proceedings of the ICE-Waste and Resource Management, Vol. 166, 187-203. http://dx.doi.org/10.1680/warm.13.00016

[4] Engstrom, R. and Carlsson-Kanyama, A. (2004) Food Losses in Food Service Institutions: Examples from Sweden. Food Policy, 29, 203-213. http://dx.doi.org/10.1016/j.foodpol.2004.03.004

[5] Kim, K., Kim, M. and Lee, K.-E. (2010) Assessment of Foodservice Quality and Identification of Improvement Strategies Using Hospital Foodservice Quality Model. Nutrition Research and Practice, 4, 162-172. http://dx.doi.org/10.4162/nrp.2010.4.2.163

[6] Grieger, J.A. and Nowson, C.A. (2007) Nutrient Intake and Plate Waste from an Australian Residential Care Facility. European Journal of Clinical Nutrition, 61, 655-663.

[7] Williams, P. and Walton, K. (2011) Plate Waste in Hospitals and Strategies for Change. e-SPEN, the European eJournal of Clinical Nutrition and Metabolism, 6, e235-e241. http://dx.doi.org/10.1016/j.eclnm.2011.09.006

[8] Ferreira, M., Martins, M.L. and Rocha, A. (2013) Food Waste as an Index of Food Service Quality. British Food Journal, 115, 1628-1637. http://dx.doi.org/10.1108/BFJ-03-2012-0051

[9] Goonan, S., Mirosa, M. and Spence, H. (2014) Getting a Taste for Food Waste: A Mixed Methods Ethnographic Study into Hospital Food Waste before Patient Consumption Conducted at Three New Zealand Foodservice Facilities. Journal of the Academy of Nutrition and Dietetics, 114, 63-71. http://dx.doi.org/10.1016/j.jand.2013.09.022

[10] Haynes, S.N., Richard, D. and Kubany, E.S. (1995) Content Validity in Psychological Assessment: A Functional Approach to Concepts and Methods. Psychological Assessment, 7, 238-247. http://dx.doi.org/10.1037/1040-3590.7.3.238

[11] Hyrkas, K., Appelqvist-Schmidlechnerb, K. and Oksa, L. (2003) Validating an Instrument for Clinical Supervision Using an Expert Panel. International Journal of Nursing Studies, 40, 619-625. http://dx.doi.org/10.1016/S0020-7489(03)00036-1

[12] Streiner, D.I. (2003) Starting at the Beginning: An Introduction to Coefficient Alpha and Internal Consistency. Journal of Personality Assessment, 80, 99-103. http://dx.doi.org/10.1207/S15327752JPA8001 18

[13] Aaronson, N., Alonso, J., Burnam, A., Lohr, K.N., Patrick, D.L., Perrin, E. and Stein, R.E. (2002) Assessing Health Status and Quality-of-Life Instruments: Attributes and Review Criteria. Quality of Life Research, 202, 193-205.

[14] Wie, S.H. and Shanklin, C.W. (2001) Cost Effective Disposal Methods and Assessment of Waste Generated in Foodservice Operations. Foodservice Research International, 13, 17-39.

http://dx.doi.org/10.1111/j.1745-4506.2001.tb00027.x 